\title{
Synthesis of Fully Aromatic Polyketones without Ether Linkages in the Main Chain. Nickel Complex-Mediated Aromatic Coupling Polymerization of Bis(chlorobenzoylated) $o$-Terphenyls
}

\author{
Katsuya MaeYama ${ }^{\dagger}$ Tadahiro OHE, Hiroyuki NAKAmURA, \\ and Noriyuki YoNEZAWA ${ }^{\dagger}$ \\ Department of Organic and Polymer Materials Chemistry, Tokyo University of Agriculture and Technology, \\ Koganei, Tokyo 184-8588, Japan
}

(Received August 22, 2003; Accepted October 10, 2003)

\begin{abstract}
Nickel complex-mediated polymerization reactions of symmetrically bis(chlorobenzoylated) oterphenyls (1a and $\mathbf{1 b}$ ) have successfully given fully aromatic polyketones, i.e., aromatic polyketones composed of only arylene and ketonic carbonyl units. Polymerization of unsymmetrically bis(chlorobenzoylated) $o$-terphenyl (1c) has also given fully aromatic polyketones bearing slightly higher molecular weight. On the other hand, copolymerization of symmetrical monomers $\mathbf{1 a}$ and $\mathbf{1 b}$ has afforded higher-molecular-weight fully aromatic polyketones, particularly in the polymerization of a 1:1 mixture of the monomers. The obtained fully aromatic polyketones have excellent thermal resistibility and enhanced solubility to organic solvents.
\end{abstract}

KEY WORDS Fully Aromatic Polyketone / Nickel Complex-Mediated Coupling Polymerization / Thermal Resistibility / Enhanced Solubility /

Aromatic polyketones are generally recognized as one of the polymers of high-performance chemical and physical properties. There are many reports concerning the synthesis of aromatic polyketones. ${ }^{1-7}$ However, almost all of the aromatic polyketones hitherto reported contain ether linkages in the main chain. In other words, these polyketones are classified as aromatic poly(ether ketone)s. In the synthesis of poly(ether ketone)s, ether linkages in the main chains are considered to prevent the precipitation of the oligomer formed at the early stage of polymerization via flexibilization of polymer chains, resulting in realization of high degree of polymerization. On the other hand, there are only a few reports ${ }^{8-11}$ concerning the synthesis of aromatic polyketones where ether linkages are excluded from the main chain, i.e., wholly aromatic polyketones, aside from our works. ${ }^{12-17}$ The bond elongation reactions applicable to the synthesis of wholly aromatic polyketones are practically restricted to the following two protocols: bond formation between aromatic carbon and carboxy one and that between aromatic carbons. As the former protocol, electrophilic aromatic substitution aroylation reaction is considered to be the most important chain elongation one. It is, however, difficult to introduce two aroyl groups in an aromatic system because an aroyl group, a strongly electron-withdrawing one, prevents the introduction of the second aroyl group onto the same aromatic system. For the introduction of two aroyl groups, severe reaction conditions are needed to overcome the low reactivity, resulting in poor regios- elective substitution. This problem presumably keeps away application of electrophilic aromatic aroylation approach for the synthesis of aromatic polyketones.

Under these circumstances, we have aimed at the synthesis of wholly aromatic polyketones through electrophilic aromatic aroylation with the aid of the molecular designing of monomers to achieve the sustainable reactivity and regioselectivity. The first successful approach is the use of 2,2'-dimethoxybiphenyl as an acylacceptant monomer. Recently, we have succeeded in preparing high-molecular-weight wholly aromatic polyketones comprised of 2,2'-dimethoxybiphenyl$5,5^{\prime}$-ene backbone by use of electrophilic aromatic aroylation polymerization. ${ }^{12,13,15-17}$ Presumably, electric and structural characteristics of $2,2^{\prime}$-dimethoxybiphenyl realize smooth and highly regioselective progress of electrophilic aromatic aroylation reactions. In addition, the twisted structure of the $2,2^{\prime}$-dimethoxybiphenyl-5, $5^{\prime}$-ene backbone formed probably suppresses aggregation of the resulting polyketones. Synthesis of wholly aromatic polyketones containing 2,2'-dimethoxy-5,5'-biphenylene backbone via nickel complex-mediated aromatic coupling polymerization has also been performed. ${ }^{13,14}$

As the next stage of the study on the synthesis of wholly aromatic polyketones, we have intended to synthesize wholly aromatic polyketones where ether linkages are excluded throughout the molecule. In this relation, we have already reported that phosphrous pentoxide-methanesulfonic acid mixture $\left(\mathrm{P}_{2} \mathrm{O}_{5^{-}}\right.$ 
$\mathrm{MsOH}$ ) mediated ready and regioselective diaroylation at 4- and $4 "$-positions of $o$-terphenyl. ${ }^{18}$ Accordingly, the structural characteristics of $o$-terphenyl derivatives, i.e., suitable twist among three phenylene rings, motivated us to synthesize wholly aromatic polyketones without ether linkage by introducing $o$-terphenylene backbone in the main chain.

Recently, we have preliminary reported the successful synthesis of fully aromatic polyketones containing $o$-terphenylene unit in the main chains through nickelcomplex mediated aromatic coupling homopolymerizations of bis(chlorobenzoylated) $o$-terphenyl monomers (1a and 1b) obtained via regioselective diaroylations of $o$-terphenyl. ${ }^{19}$ In this paper, we would like to discuss in detail the nickel complex-mediated aromatic coupling homo- and copolymerization of these monomers to yield fully aromatic polyketones having good thermal resistibility and syntheses of fully aromatic polyketone with the disordered alignment of repeating units, i.e., polymerization of unsymmetrical monomer $\mathbf{1 c}$.

\section{EXPERIMENTAL}

\section{General}

${ }^{1} \mathrm{H}$ NMR and ${ }^{13} \mathrm{C}$ NMR spectra were recorded on a JEOL A-500 $\left({ }^{1} \mathrm{H}\right.$ NMR, $500 \mathrm{MHz} ;{ }^{13} \mathrm{C}$ NMR, $125 \mathrm{MHz})$ spectrometer in $\mathrm{CDCl}_{3}$ with TMS $(\delta=0.00)$ and $\mathrm{CDCl}_{3}(\delta=77.0)$ as internal standards. IR spectra were recorded on a JEOL FTIR-5300 spectrometer. The degree of polymerization was estimated by polystyrene calibration using GPC. GPC was performed with a Shodex $\mathrm{KD}-806 \mathrm{M}$ column at $40^{\circ} \mathrm{C}$ using $\mathrm{CHCl}_{3}$ as the eluent. The UV absorption was traced by a Hitachi L-7405 UV detector ( $300 \mathrm{~nm}$ ). Glass transition temperatures ( $T_{\mathrm{g}}$ 's) were determined on the basis of DSC curves of the resulting polymers. DSC curves were recorded on a SEIKO DSC 200 differential scanning calorimeter with a heating rate of $10 \mathrm{~K} \mathrm{~min}^{-1}$ under nitrogen. Thermal degradation temperatures $\left(T_{\mathrm{d}}\right.$ 's) were determined on the basis of TGA thermograms of the polymers. TGA thermograms were recorded on a SEIKO TG/DTA-200 thermogravimeter with a heating rate of $10 \mathrm{~K} \mathrm{~min}^{-1}$ under nitrogen. Inherent viscosity was determined by measurement of the flow time of a polymer solution in concentrated $\mathrm{H}_{2} \mathrm{SO}_{4}\left(0.3 \mathrm{~g} \mathrm{dL}^{-1}\right)$ at $30^{\circ} \mathrm{C}$ using an Ostwald viscometer.

\section{Materials}

$\mathrm{NiBr}_{2}$ was dried at $220^{\circ} \mathrm{C}$ for $2 \mathrm{~h}$ under reduced pressure just before use. $\mathrm{Zn}$ (400 mesh) was activated by stirring with distilled acetic acid, collecting by filtration, washing thoroughly with distilled water, and drying under vacuum. $\mathrm{PPh}_{3}$ and 2,2'-bipyridyl (bpy) were recrystallized from dehydrated hexane. $\mathrm{N}, \mathrm{N}$ dimethylacetamide (DMAc) was distilled under reduced pressure from powdered $\mathrm{CaH}_{2}$ just before use. $\mathrm{P}_{2} \mathrm{O}_{5}-\mathrm{MsOH}$ was prepared according to the reported procedure. ${ }^{20}$ Monomers 1a-1c were prepared according to our previous paper. ${ }^{18}$

\section{Polymerization of Monomers $\mathbf{1 a}-\mathbf{1 c}$}

4,4"-Bis(chlorobenzoyl)-1, $1^{\prime}: 2^{\prime}, 1^{\prime \prime}$-terphenyl (1, $0.25 \mathrm{mmol}, 126 \mathrm{mg}), \mathrm{NiBr}_{2}(0.125 \mathrm{mmol}, 29.4 \mathrm{mg})$, triphenylphosphine $(0.25 \mathrm{mmol}, \quad 65.6 \mathrm{mg}), \quad 2,2^{\prime}-$ bipyridyl $(0.125 \mathrm{mmol}, 19.3 \mathrm{mg})$, and $\mathrm{Zn}(0.776 \mathrm{mmol}$, $50.5 \mathrm{mg}$ ) were placed in a two-necked round flask and to this mixture, freshly distilled DMAc was added via a syringe. The reaction mixture was stirred at $100^{\circ} \mathrm{C}$ (for monomer 1a and $\mathbf{1 b}$ ) or $120^{\circ} \mathrm{C}$ (for monomer 1c) for $2 \mathrm{~h}$. The mixture was diluted with DMAc and the solution was poured dropwise into a hydrochloric $\mathrm{acid} /$ methanol solution $(1.2 \mathrm{M})$ with stirring to separate out a solid. The solid was filtrated and washed with methanol and acetone in turn. The precipitates were dried under reduced pressure at $80^{\circ} \mathrm{C}$ to give polymer 2.

Polymer 2a: IR (KBr): 1657, 1603, 1399, 1312, 1277, 928, $754 \mathrm{~cm}^{-1} .{ }^{1} \mathrm{H}$ NMR $\delta\left(\mathrm{CDCl}_{3}\right): 7.30-$ 7.34 $(4 \mathrm{H}, \mathrm{m}), 7.52(4 \mathrm{H}$, pseudo s $), 7.70-7.75(8 \mathrm{H}, \mathrm{m})$, 7.88-7.90(4 H, m) ppm. ${ }^{13} \mathrm{C} \mathrm{NMR} \delta\left(\mathrm{CDCl}_{3}\right): 127.2$, 127.3, 128.3, 128.4, 129.7, 129.8, 129.9, 129.9, 130.0, 130.7, 130.8, 132.4, 135.7, 137.0, 139.5, 143.7, 145.6, 195.6 ppm. Anal. Calcd. For $\left(\mathrm{C}_{32} \mathrm{H}_{20} \mathrm{O}_{2}\right)_{\mathrm{n}}, \mathrm{C} 88.04, \mathrm{H}$ $4.62 \%$. Found. C $87.05, \mathrm{H} 4.98 \%$.

Polymer 2b: IR (KBr): 1657, 1603, 1400, 1279, 939, $752 \mathrm{~cm}^{-1} .{ }^{1} \mathrm{H}$ NMR $\delta\left(\mathrm{CDCl}_{3}\right): 7.24-7.31(4 \mathrm{H}$, $\mathrm{m}), 7.52(6 \mathrm{H}$, pseudo s), 7.73-7.78(8 H, m), 7.968.03(2 H, m) ppm. ${ }^{13} \mathrm{C}$ NMR $\delta\left(\mathrm{CDCl}_{3}\right): 127.5,128.0$, $128.1,128.3,128.4,129.0,129.3,129.6,129.8,130.0$, 130.7, 131.0, 131.2, 132.3, 135.6, 135.8, 137.6, 139.5, 145.5, 145.7, 195.8, 196.0 ppm. Anal. Calcd. for $\left(\mathrm{C}_{32} \mathrm{H}_{20} \mathrm{O}_{2}\right)_{n}, \mathrm{C} 88.04, \mathrm{H} 4.62 \%$. Found. C 87.01, H $4.72 \%$.

Polymer 2c: IR (KBr): 1657, 1603, 1399, 1277, 930, 752, $700 \mathrm{~cm}^{-1} .{ }^{1} \mathrm{H}$ NMR $\delta\left(\mathrm{CDCl}_{3}\right): 7.25-$ 7.32(4 H, m), 7.46-7.52(4 H, m), 7.66-7.77(8 H, m), 7.78-7.88(2 H, m), 7.97-8.05(2 H, m) ppm. ${ }^{13} \mathrm{C}$ NMR $\delta\left(\mathrm{CDCl}_{3}\right): 127.2,127.3,128.3,128.4,129.7$, $129.8,129.9,130.0,130.7,130.8,132.4,135.7,137.0$, $139.5,143.7,145.6,195.6 \mathrm{ppm}$. Anal. Calcd. For $\left(\mathrm{C}_{32} \mathrm{H}_{20} \mathrm{O}_{2}\right)_{n}, \mathrm{C} 88.04, \mathrm{H} 4.62 \%$. Found. C 87.01, H $4.72 \%$.

\section{Copolymerization of Monomers $\mathbf{1} \boldsymbol{a}$ and $\mathbf{1 b}$}

In a two-necked round flask, 4,4"-bis(4-chlorobenzoyl)-1,1': $2^{\prime}, 1^{\prime \prime}$-terphenyl (1a, $0.125 \mathrm{mmol}, 62.0$ 
mg), 4,4' (1b, $0.125 \mathrm{mmol}, \quad 62.0 \mathrm{mg}), \quad \mathrm{NiBr}_{2} \quad(0.125 \mathrm{mmol}$, $27.4 \mathrm{mg})$, triphenylphosphine $(0.25 \mathrm{mmol}, 65.6 \mathrm{mg})$, $2,2^{\prime}$-bipyridyl $(0.125 \mathrm{mmol}, \quad 19.4 \mathrm{mg})$, and $\mathrm{Zn}$ $(0.776 \mathrm{mmol}, 50.4 \mathrm{mg})$ were placed and to this mixture, freshly distilled DMAc $(0.5 \mathrm{~mL})$ was added via a syringe. The reaction mixture was stirred at $100^{\circ} \mathrm{C}$ for $8 \mathrm{~h}$. The reaction mixture was diluted with DMAc and the solution was poured dropwise into a hydrochloric acid/methanol solution (1.2 M) with stirring to separate out a solid. The solid was filtrated and washed with methanol and acetone in turn. The insoluble fraction was evacuated under reduced pressure at $80{ }^{\circ} \mathrm{C}$ to give copolymer $\mathbf{2 d}$.

IR (KBr): 1659, 1603, 1275, 930, 855, $750 \mathrm{~cm}^{-1} .{ }^{1} \mathrm{H}$ NMR $\delta\left(\mathrm{CDCl}_{3}\right): 7.31-7.39(4 \mathrm{H}, \mathrm{m}), 7.50(5 \mathrm{H}$, pseudo s), $7.75(8 \mathrm{H}$, pseudo s), 7.82 (2 H, pseudo s), 7.98-8.02 $\left(1 \mathrm{H}\right.$, pseudo s) ppm. ${ }^{13} \mathrm{C}$ NMR $\delta\left(\mathrm{CDCl}_{3}\right)$ : 127.0, $127.1,128.2,128.3,128.5,128.8,129.9,130.0,130.4$, 130.6, 130.8, 130.9, 135.5, 135.7, 136.7, 137.0, 138.2, $138.3,139.4,139.4,140.1,140.3,143.7,143.9,145.5$, 145.6, 145.6, 145.7, 195.7, 196.0 ppm. Anal. Calcd. for $\left(\mathrm{C}_{32} \mathrm{H}_{20} \mathrm{O}_{2}\right)_{\mathrm{n}}, \mathrm{C} 88.04, \mathrm{H} 4.62 \%$. Found. C 87.20, $\mathrm{H} 4.81 \%$.

\section{RESULTS AND DISCUSSION}

\section{Polymerization of 4,4"-Bis(4-chlorobenzoylated) o- Terphenyl (1a)}

We have recently reported diaroylation of $o$ terphenyl at the 4,4"'-positions proceeds with the aid of $\mathrm{P}_{2} \mathrm{O}_{5}-\mathrm{MsOH}$, affording the corresponding diaroylated product in good yields. ${ }^{18}$ Then, we attempted to apply this protocol to polyketone synthesis as $\mathrm{P}_{2} \mathrm{O}_{5}$ $\mathrm{MsOH}$ mediated direct condensation polymerization. The reaction of $o$-terphenyl with terephthalic acid in $\mathrm{P}_{2} \mathrm{O}_{5}-\mathrm{MsOH}$, however, yielded no polymerized products and the starting materials were recovered instead. This result shows that $o$-terphenyl, where no strong electron-donating groups are included, has a lower reactivity as an acyl-acceptant monomer than 2,2'-dimethoxybiphenyl. ${ }^{12,17}$ In this course, we have investigated the synthetic method for fully aromatic polyketones having $o$-terphenylene unit by polymerization of bifunctionalized $o$-terphenyl, i.e., nickel complex mediated aromatic coupling polymerization of bis(chlorobenzoylated) $o$-terphenyls.

Table I shows the results of nickel complexmediated aromatic coupling polymerization of $4,4^{\prime \prime}$ bis(4-chlorobenzoyl)-1, $1^{\prime}: 2^{\prime}, 1^{\prime \prime}$-terphenyl (1a) in $N, N$ dimethylacetamide (DMAc), $N, N$-dimethylformamide (DMF), chloroform, and 1,4-dioxane, under the conditions of $50 \mathrm{~mol} \%$ of $\mathrm{NiBr}_{2}, 310 \mathrm{~mol} \%$ of $\mathrm{Zn}, 50 \mathrm{~mol} \%$
Table I. Nickel complex-mediated aromatic coupling polymerization of monomer 1a in several solvents

\begin{tabular}{clcr}
\hline Run & Solvent & Yield/\% & $\bar{M}_{\mathrm{n}}{ }^{\mathrm{a}}$ \\
\hline $1^{\mathrm{b}}$ & DMAc & 95 & 8000 \\
$2^{\mathrm{b}}$ & DMF & 96 & 5000 \\
3 & $\mathrm{CHCl}_{3}$ & 0 & - \\
4 & Dioxane & 0 & - \\
\hline
\end{tabular}

Reaction conditions: monomer, $0.125 \mathrm{mmol}$; $\mathrm{Zn}$, 0.388 mmol; $\mathrm{NiBr}_{2}, 0.0625 \mathrm{mmol} ; \mathrm{NiBr}_{2}: 2,2^{\prime}$-bipyridyl: $\mathrm{PPh}_{3}=1: 1: 2$; Solvent, $0.25 \mathrm{~mL}$. ${ }^{\mathrm{a}}$ Calculated on the basis of GPC measurement (Column, Shodex GPC KD-806M; Eluent, $\mathrm{CHCl}_{3}$; UV detector; $\left.300 \mathrm{~nm}\right)$. ${ }^{\mathrm{b}}$ Reaction temperature, $100{ }^{\circ} \mathrm{C}$.

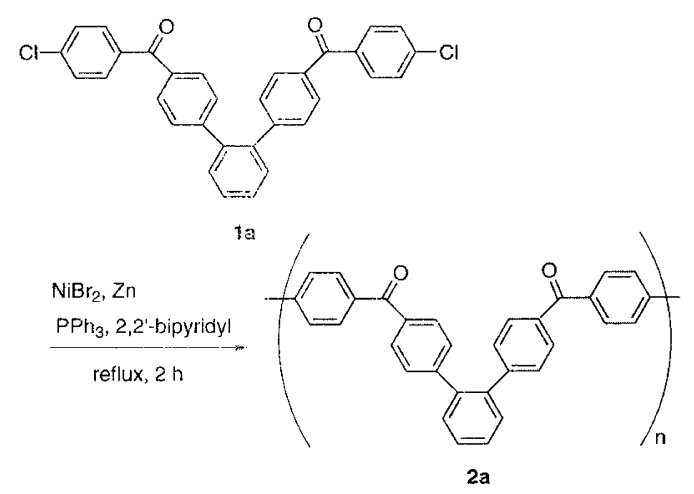

Scheme 1. Nickel complex-mediated aromatic coupling polymerization of monomer $\mathbf{1 a}$.

of 2,2'-bipyridyl (bpy), and $100 \mathrm{~mol} \%$ of $\mathrm{PPh}_{3}$ against monomer 1a (Scheme 1). The degree of polymerization was estimated by polystyrene calibration using gel permeation chromatography (GPC).

Among solvents screened, DMAc is the most effective one (Run 1). $\mathrm{CHCl}_{3}$ or 1,4-dioxane is less suitable for a solvent in the polymerization, resulting in recovery of starting material. The acceleration of reaction in aprotic and polar solvents is probably due to the higher solubility of nickel complex intermediates in these solvents.

Reaction with 50 and $100 \mathrm{~mol} \%$ of nickel catalyst against monomer 1a gave high-molecular-weight polyketones (Runs 3 and 4). The maximum $M_{\mathrm{n}}$ of the polyketone was obtained when the reaction was undertaken at $100^{\circ} \mathrm{C}$ for $2 \mathrm{~h}$. This result indicates that the polymerization of monomer 1a requires short reaction time and high reaction temperature. The resulting polyketone (2a) shows higher solubility in organic solvents than the wholly aromatic polyketones containing 2,2'-dimethoxybiphenylene. ${ }^{12,14,17}$ Actually, the resulting polyketone (2a) is soluble not only in halogenated solvents such as chloroform and chlorobenzene but also in ethereal solvents such as 1,4-dioxane and tetrahydrofuran (THF). Furthermore, it is also soluble in toluene, DMF, and DMSO by heating. This nature is observed in the case of the poly(ether ketone)s 
Table II. Nickel complex-mediated aromatic coupling polymerization of monomer 1a

\begin{tabular}{|c|c|c|c|c|c|}
\hline Run & $\frac{\mathrm{NiBr}_{2}}{\mathrm{~mol} \%}$ & $\frac{\text { Temperature }}{{ }^{\circ} \mathrm{C}}$ & $\frac{\text { Time }}{\mathrm{h}}$ & $\frac{\text { Yield }}{\%}$ & $\bar{M}_{\mathrm{n}}{ }^{\mathrm{a}}$ \\
\hline 1 & 5 & 100 & 2 & 64 & 1700 \\
\hline 2 & 25 & 100 & 2 & 82 & 6600 \\
\hline 3 & 50 & 100 & 2 & 95 & 8000 \\
\hline 4 & 100 & 100 & 2 & 96 & 7000 \\
\hline 5 & 50 & 100 & 1 & 59 & 5000 \\
\hline 6 & 50 & 100 & 3 & 86 & 5500 \\
\hline 7 & 50 & 60 & 2 & 92 & 5700 \\
\hline 8 & 50 & 80 & 2 & 89 & 6600 \\
\hline
\end{tabular}

Reaction conditions: monomer, $0.125 \mathrm{mmol}$; $\mathrm{Zn}, 0.388$ mmol; $\mathrm{NiBr}_{2}:$ 2,2'-bipyridyl: $\mathrm{PPh}_{3}=1: 1: 2$; DMAc (solvent), $0.25 \mathrm{~mL}$. ${ }^{\mathrm{a}}$ Calculated on the basis of GPC measurement (Column, Shodex GPC KD-806M; Eluent, $\mathrm{CHCl}_{3}$; UV detector; $300 \mathrm{~nm})$.

and the polyamide containing $o$-terphenylene units prepared by Akutsu and his coworkers ${ }^{21,22}$ and probably depends on the structural peculiarity of $o$-terphenylene unit. $o$-Terphenylene units probably afford flexibility to the polymers due to the twist of among benzene rings, which improves solubility in various organic solvents. In addition, the resulting polyketone (2a) was cast from chloroform giving a transparent and colorless flexible film. The flexibility in the fully aromatic polyketones is probably performed by the twisted aromatic ring assemblies, i.e., $o$-terphenylene units, as is achieved by introducing ether linkages in the main chain in aromatic poly(ether ketone).

\section{Polymerization of the Regioisomeric Monomer (1b)}

Table III shows the results of polymerization of $4,4^{\prime \prime}$ bis(3-chlorobenzoylated) $o$-terphenyl monomer (1b) under several sets of reaction conditions. The highest number average molecular weight, $M_{\mathrm{n}}$, determined by GPC calibration with polystyrene standards, was obtained in the polymerization of monomer $\mathbf{1 b}$ under the same reaction conditions where monomer 1a gave the corresponding polyketone of the highest number average molecular weight.

In general, introduction of 3,3'-biphenylene units to polymer backbone in place of rigid 4,4'-biphenylene units is assessed to improve the solubility of the resulting polymers. The resulting polymer (2b) has, however, lower solubility in chloroform than polymer 2a. Particularly, the polymer obtained by treatment of monomer 1b with an equimolar amount of $\mathrm{NiBr}_{2}$ is insoluble in chloroform (Run 3), though the inherent viscosity of the polymer is low.

Lower solubility of polyketone $\mathbf{2 b}$ in organic solvents than polyketone 2a presumably depends on the rather flexible structure of the main chain of polyke-
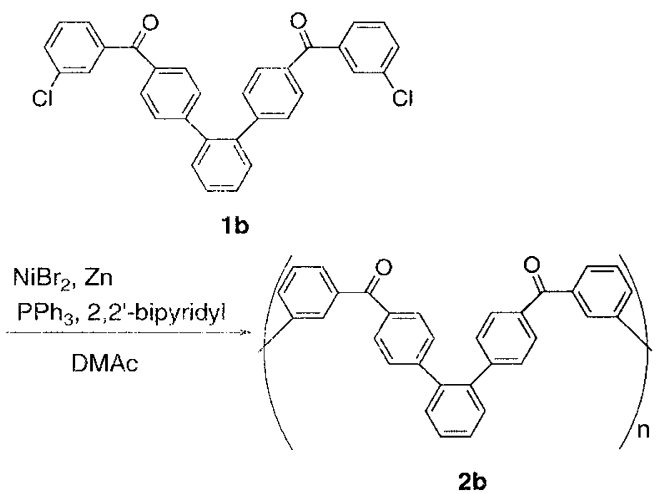

Scheme 2. Nickel complex-mediated aromatic coupling polymerization of monomer $\mathbf{1 b}$.

Table III. Nickel complex-mediated aromatic coupling polymerization of monomer $\mathbf{1 b}$.

\begin{tabular}{|c|c|c|c|c|c|c|}
\hline Run & $\frac{\mathrm{NiBr}_{2}}{\mathrm{~mol} \%}$ & $\frac{\text { Temperature }}{{ }^{\circ} \mathrm{C}}$ & $\frac{\text { Time }}{\mathrm{h}}$ & $\frac{\text { Yield }}{\%}$ & $\bar{M}_{\mathrm{n}}^{\mathrm{a}}$ & $\frac{\eta_{\text {inh }}{ }^{\mathrm{b}}}{\mathrm{dL} \mathrm{g}^{-1}}$ \\
\hline 1 & 50 & 100 & 2 & 92 & 8000 & 0.19 \\
\hline 2 & 25 & 100 & 2 & 82 & 6300 & 0.12 \\
\hline 3 & 100 & 100 & 2 & 80 & $-^{\mathrm{c}}$ & 0.03 \\
\hline 4 & 50 & 80 & 2 & 97 & 4600 & 0.11 \\
\hline 5 & 50 & 100 & 1 & 84 & 1000 & 0.04 \\
\hline 6 & 50 & 100 & 4 & 95 & 2700 & 0.06 \\
\hline
\end{tabular}
$0.388 \mathrm{mmol}: \mathrm{NiBr}_{2}: 2,2^{\prime}$-bipyridyl: $\mathrm{PPh}_{3}=1: 1: 2 ;$ DMAc, $0.25 \mathrm{~mL}$. ${ }^{\mathrm{a}}$ Calculated on the basis of GPC measurement (Column, Shodex GPC KD-806M; Eluent, $\mathrm{CHCl}_{3}$; UV detector, $300 \mathrm{~nm})$. ${ }^{\mathrm{b}}$ Determined in a concentrated $\mathrm{H}_{2} \mathrm{SO}_{4}$ solution $(0.3 \mathrm{~g}$ $\left.\mathrm{dL}^{-1}\right)$ at $30^{\circ} \mathrm{C}$. ${ }^{\mathrm{c}}$ Not measured.

tone $\mathbf{2 b}$. The backbone of polyketone 2a probably has a stretched nature where twisted $o$-terphenylene units and rigid 4,4'-biphenylene units align alternately. On the other hand, the twisted $o$-terphenylene units and crankshaft-like 3,3'-biphenylene units aligned alternately in polyketone $\mathbf{2 b}$ presumably make the main chain bent and folded. As the backbone of polyketone $\mathbf{2 b}$ is in such manner sterically more hindered than that of polyketone 2a, solvent molecules are probably prevented from solvating the polymer chains, which decreases the solubility of the polyketone in organic solvents.

\section{Homopolymerization of Unsymmetrically Bis(chloro-} benzoylated) Monomer $1 \mathrm{c}$

The unsymmetrically bis(chlorobenzoylated) monomer (1c) was prepared via $\mathrm{P}_{2} \mathrm{O}_{5}-\mathrm{MsOH}$ mediated mono-chlorobenzoylation of $o$-terphenyl stepwise (Scheme 3). ${ }^{18}$

The optimal conditions are the same as those for polymerization of symmetrical monomers $\mathbf{1 a}$ and $\mathbf{1 b}$. In addition, polymerization of monomer $1 \mathbf{c}$ was almost completed within $1 \mathrm{~h}$. This fact means that the reactivity of unsymmetrical monomer 1c is higher than 


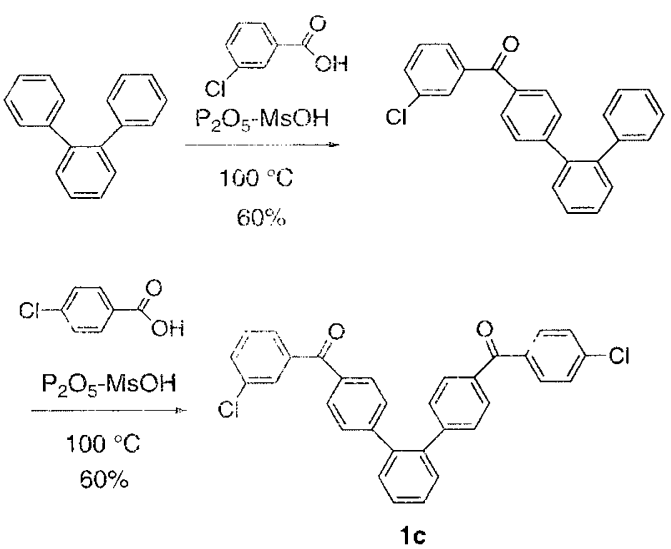

Scheme 3. Preparation of unsymmetrical monomer 1c.

Table IV. Polymerization of unsymmetrical monomer 1c
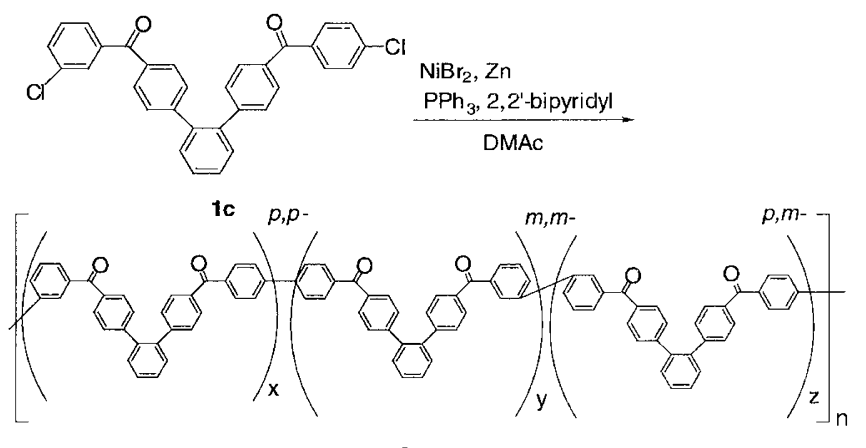

\begin{tabular}{|c|c|c|c|c|c|c|}
\hline Run & $\frac{\mathrm{NiBr}_{2}}{\mathrm{~mol} \%}$ & $\frac{\text { Temperature }}{{ }^{\circ} \mathrm{C}}$ & $\frac{\text { Time }}{\mathrm{h}}$ & $\frac{\text { Yield }}{\%}$ & $\frac{\eta_{\text {inh }}}{\mathrm{dL}^{-1 \mathrm{a}}}$ & $\bar{M}_{\mathrm{n}}^{\mathrm{b}}$ \\
\hline 1 & 50 & 100 & 2 & 98 & 0.18 & 8000 \\
\hline 2 & 25 & 100 & 2 & 89 & 0.11 & 5100 \\
\hline 3 & 100 & 100 & 2 & 91 & 0.14 & 6800 \\
\hline 4 & 50 & 100 & 1 & 94 & 0.19 & 8000 \\
\hline 5 & 50 & 60 & 2 & 97 & 0.18 & 6100 \\
\hline 6 & 50 & 80 & 2 & 98 & 0.20 & 6800 \\
\hline 7 & 50 & 120 & 2 & 98 & 0.20 & 8200 \\
\hline
\end{tabular}

Reaction conditions: monomer, $0.125 \mathrm{mmol} ; \mathrm{Zn}, 0.388$ mmol; $\mathrm{NiBr}_{2}$ : 2,2'-bipyridyl: $\mathrm{PPh}_{3}=1: 1: 2 ;$ DMAc, $0.25 \mathrm{~mL}$. ${ }^{a}$ Determined in a concentrated $\mathrm{H}_{2} \mathrm{SO}_{4}$ solution $\left(0.3 \mathrm{~g} \mathrm{dL}^{-1}\right)$ at $30{ }^{\circ} \mathrm{C}$. ${ }^{b}$ Calculated on the basis of GPC measurement (Column, Shodex GPC KD-806M; Eluent, $\mathrm{CHCl}_{3}$; UV detector, $300 \mathrm{~nm}$ ).

those of symmetrical monomers $\mathbf{1 a}$ and $\mathbf{1 b}$, though little improvement of the degree of polymerization is achieved and the resulting polymer (2c) easily dissolves in $\mathrm{CHCl}_{3}$.

\section{Copolymerization of Symmetrical Monomers $\mathbf{1 a}$ and $\mathbf{1 b}$}

As shown in Table V, copolymerization of equimolar amounts of the two symmetrically bis(chlorobenzoylated) $o$-terphenyls (1a and $\mathbf{1 b})$ readily afforded copolyketone $\mathbf{2 d}$.

The polymerization reaction was completed almost within $1 \mathrm{~h}$ (Runs 2 and 6). This means that copolymerization proceeds more rapidly than homopolymerization of monomers 1a and $\mathbf{1 b}$. Further, the sequence of
Table V. Copolymerization of monomers $\mathbf{1 a}$ and $\mathbf{1 b}$
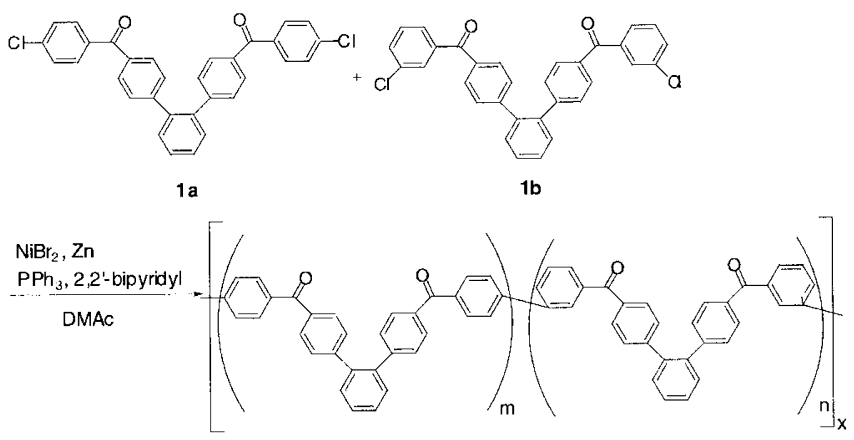

2d

\begin{tabular}{|c|c|c|c|c|c|c|}
\hline Run & $\frac{\mathrm{NiBr}_{2}}{\mathrm{~mol}^{2}}$ & $\frac{\text { Temperature }}{{ }^{\circ} \mathrm{C}}$ & $\frac{\text { Time }}{\mathrm{h}}$ & $\frac{\text { Yield }}{\%}$ & $\frac{\eta_{\text {inh }}}{\mathrm{dL}^{-1 \mathrm{a}}}$ & $\bar{M}_{\mathrm{n}}^{\mathrm{b}}$ \\
\hline 1 & 25 & 100 & 2 & 99 & 0.21 & 9100 \\
\hline 2 & 50 & 100 & 2 & 96 & 0.30 & 10200 \\
\hline 3 & 100 & 100 & 2 & 96 & 0.18 & 7400 \\
\hline 4 & 50 & 80 & 2 & 96 & 0.14 & 6200 \\
\hline 5 & 50 & 120 & 2 & 99 & 0.11 & 5200 \\
\hline 6 & 50 & 100 & 1 & 96 & 0.26 & 10200 \\
\hline 7 & 50 & 100 & 3 & 96 & 0.30 & 9700 \\
\hline
\end{tabular}

Reaction conditions: each monomer (1a, 1b), $0.0625 \mathrm{mmol}$; Zn, 0.388 mmol; $\mathrm{NiBr}_{2}:$ 2,2'-bipyridyl: $\mathrm{PPh}_{3}=1: 1: 2$; DMAc,

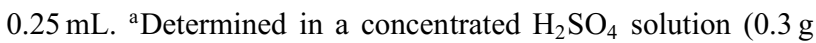
$\left.\mathrm{dL}^{-1}\right)$ at $30^{\circ} \mathrm{C}$. ${ }^{b}$ Calculated on the basis of GPC measurement (Column, Shodex GPC KD-806 M; Eluent, $\mathrm{CHCl}_{3}$; UV detector, $300 \mathrm{~nm})$.

Table VI. Copolymerization of monomers $\mathbf{1 a}$ and $\mathbf{1 b}$ in several fractions

\begin{tabular}{ccccc}
\hline Run & $\begin{array}{l}\text { Fraction of } \\
\text { monomer } \mathbf{1 b}\end{array}$ & $\begin{array}{c}\text { Yield } \\
\text { \% }\end{array}$ & $\frac{\eta_{\text {inh }}{ }^{\mathrm{a}}}{\mathrm{dL} \mathrm{g}^{-1}}$ & $\bar{M}_{\mathrm{n}}{ }^{\mathrm{b}}$ \\
\hline 1 & 0 & 95 & 0.23 & 8000 \\
2 & 0.2 & 98 & 0.18 & 6900 \\
3 & 0.25 & 98 & 0.24 & 8400 \\
4 & 0.4 & 96 & 0.21 & 9800 \\
5 & 0.5 & 96 & 0.30 & 10200 \\
6 & 0.6 & 97 & 0.20 & 9200 \\
7 & 0.75 & 98 & 0.12 & 4800 \\
8 & 0.8 & 82 & 0.10 & 4600 \\
9 & 1 & 92 & 0.19 & 8000 \\
\hline
\end{tabular}

Reaction conditions: monomers (1a and $\mathbf{1 b}), 0.125 \mathrm{mmol}$ in all; $\mathrm{Zn}, 0.388 \mathrm{mmol} ; \mathrm{NiBr}_{2}$ : 2,2'-bipyridyl: $\mathrm{PPh}_{3}=1: 1: 2$; DMAc, $0.25 \mathrm{~mL}, 100^{\circ} \mathrm{C}, 2 \mathrm{~h}$. ${ }^{\mathrm{a}}$ Determined in a concentrated $\mathrm{H}_{2} \mathrm{SO}_{4}$ solution $\left(0.3 \mathrm{~g} \mathrm{dL}^{-1}\right)$ at $30^{\circ} \mathrm{C}$. ${ }^{\mathrm{b}} \mathrm{Calculated}$ on the basis of GPC measurement (Column, Shodex GPC KD-806M; Eluent, $\mathrm{CHCl}_{3}$; UV detector, $300 \mathrm{~nm}$ ).

copolymer $\mathbf{2 d}$ has been proved random based on the ${ }^{1} \mathrm{H}$ NMR analysis. As the random alignment is considered to mean that there are no remarkable difference in the reactivity of monomers $\mathbf{1 a}$ and $\mathbf{1 b}$, smooth formation of the copolymer is assumably due to the flexible structure of the copolymer.

Table VI shows the results of copolymerization of monomers $\mathbf{1 a}$ and $\mathbf{1 b}$ in various fractions. The results 


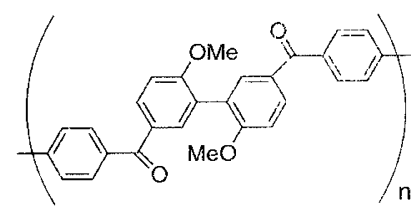

$3 a$

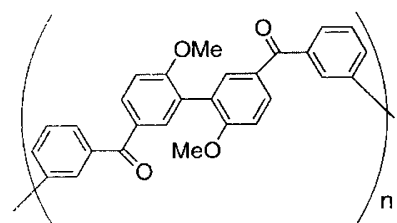

3b
Figure 1. Structures of wholly aromatic polyketones 3a and 3b.

Table VII. Thermal properties of polyketones $\mathbf{2 a - 2 d}$

\begin{tabular}{ccc}
\multicolumn{3}{c}{ and 3a, 3b } \\
\hline polymer & $\frac{T_{\mathrm{g}}}{{ }^{\circ} \mathrm{C}}$ & $\frac{T_{\mathrm{d}}}{{ }^{\circ} \mathrm{C}^{\mathrm{a}}}$ \\
\hline $\mathbf{2 a}$ & 176 & 560 \\
$\mathbf{2 b}$ & 156 & 563 \\
$\mathbf{2 c}$ & 183 & 564 \\
$\mathbf{2 d}$ & 189 & 562 \\
$\mathbf{3 a}$ & 218 & 450 \\
$\mathbf{3 b}$ & 189 & $-{ }^{\mathrm{b}}$ \\
\hline
\end{tabular}

${ }^{a}$ Temperature where a $5 \mathrm{wt} \%$ weight loss was recorded by TG. ${ }^{\text {bNot mea- }}$ sured.

indicate that copolymerization of a 1:1 mixture of the monomers gives the highest-molecular-weight polyketone. The polyketone is cast from chloroform giving a transparent and colorless flexible film. More random alignment of polymer chains, i.e., break of wellregulated alignment, probably restrains the precipitation of the resulting polymer, which realizes sustainable polymerization. In fact, sequence of copolymer 2d is not alternate but random on the basis of ${ }^{1} \mathrm{H}$ NMR spectra.

\section{Thermal Properties of the Resulting Polyketones (2)}

Table VII shows thermal properties of the wholly aromatic polyketones containing $o$-terphenylene backbone or 2,2'-dimethoxybiphenylene one. DSC analysis of polyketones $\mathbf{2 a - 2 d}$ displays glass transitions at 156$189^{\circ} \mathrm{C}$ and no detectable melting transitions before thermal decomposition. $T_{\mathrm{g}}$ 's of polyketones $\mathbf{2 a}-\mathbf{2 d}$ are lower than that of the wholly aromatic polyketone (3a) which was obtained via $\mathrm{AlCl}_{3}$-mediated Friedel-Crafts acylation polymerization of $2,2^{\prime}$-dimethoxybiphenyl and terephthaloyl chloride. ${ }^{12-17}$ Decrease of amount of the polar groups by removal of ether linkage presumably brings about drop in $T_{\mathrm{g}}$. However, the $T_{\mathrm{g}}$ 's of polyketones $\mathbf{2 a}-\mathbf{2 d}$ are higher than that of poly(ether ether ketone) (PEEK).

Figure 2 shows the TG thermogram of the copolyketone (2d) obtained in the polymerization of a 1:1 mixture of monomers. The copolymer (2d) showed a 5\% weight loss in $\mathrm{N}_{2}$ at $562{ }^{\circ} \mathrm{C}$. Other polyketones (2a2c) show almost the same thermal resistability. Higher thermal resistability of polyketones $(\mathbf{2 a}-\mathbf{2 d})$ than that

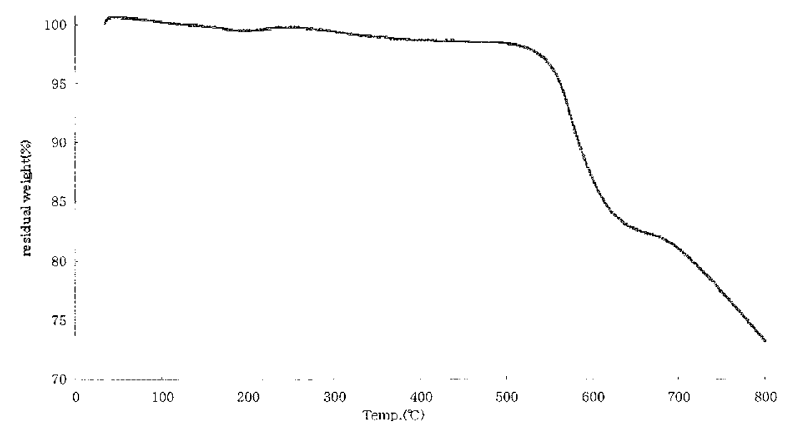

Figure 2. TG diagram of copolyketone 2d.

of polyketone 3a is considered to depend on perfect removal of polar single bonds, i.e., ether linkages, from the molecule. ${ }^{17}$

\section{CONCLUSION}

Nickel complex-mediated aromatic coupling polymerization of three regioisomeric bis(chlorobenzoylated) $o$-terphenyl 1a-1c gives fully aromatic polyketones with sufficient degree of polymerization. In addition, copolymerization of monomers 1a and 1b affords the higher-molecular-weight polyketone than homopolymerization of monomers 1a-1c. The resulting aromatic polyketones demonstrate high thermal resistability and good solubility to organic solvents.

Acknowledgments. This work was supported by SANEYOSHI SCHOLARSHIP FOUNDATION and the Ministry of Education, Culture, Sports, Science, and Technology of Japan.

\section{REFERENCES}

1. T. E. Attwood, P. C. Dawson, J. L. Freeman, L. R. J. Hoy, J. B. Rose, and P. A. Staniland, Polymer, 22, 1096 (1981).

2. M. J. Mullins and E. P. Woo, J. Macromol. Sci. Rev., Macromol. Chem. Phys., 27, 313 (1987).

3. P. A. Staniland, in "Comprehensive Polymer Science", 2 ed, G. C. Eastmond, A. Ledwith, S. Russo, and P. Sigwalt, Ed., Pergamon Press, Oxford, 1989, vol. 5, p. 483.

4. A. Pandya, J. Yang, and H. W. Gibson, Macromolecules, 27, 1367 (1994).

5. M. Ueda, Synlett, 605 (1992).

6. N. Yonezawa, J. Synth. Org. Chem. Jpn., 53, 172 (1995).

7. N. Yonezawa, S. Mori, S. Miyata, Y. Ueha-Anyashiki, and K. Maeyama, React. Funct. Polym., 53, 11 (2002).

8. M. Bochmann and K. Kelley, J. Chem. Soc., Chem. Commun., 532 (1989).

9. M. Rehahn, A. -D. Schlueter, and G. Wegner, Makromol. Chem., Rapid. Commun., 11, 535 (1990).

10. J. S. Moore, Makromol. Chem., Rapid. Commun., 13, 91 (1992).

11. M. Bochmann and J. Lu, J. Polym. Sci., Part A: Polym. Chem., 


\section{Synthesis of Fully Aromatic Polyketones}

32, 2493 (1994).

12. N. Yonezawa, S. Miyata, T. Nakamura, S. Mori, Y. Ueha, and R. Katakai, Macromolecules, 26, 5362 (1993).

13. N. Yonezawa, T. Namie, T. Ikezaki, T. Hino, H. Nakamura, Y. Tokita, and R. Katakai, React. Funct. Polym., 30, 261 (1996).

14. N. Yonezawa, T. Ikezaki, H. Nakamura, and K. Maeyama, Macromolecules, 33, 8125 (2000).

15. K. Maeyama, T. Namie, H. Nakamura, and N. Yonezawa, Recent Progress in Polycondensation, 173 (2002).

16. N. Yonezawa, H. Nakamura, and K. Maeyama, React. Funct. Polym., 52, 19. (2002)
17. N. Yonezawa, S. Miyata, S. Mori, Y. Anyashiki-Ueha, S. M. Wu, and K. Maeyama, Polym. J., 35, 998 (2003).

18. N. Yonezawa, H. Nakamura, T. Ohe, and K. Maeyama, Synth. Commun., in press.

19. K. Maeyama, T. Ohe, H. Nakamura, and N. Yonezawa, Polym. J., 35, 290 (2003).

20. P. E. Eaton and G. R. Carlson, J. Org. Chem., 38, 4071 (1973).

21. F. Akutsu, K. Takahashi, Y. Kasashima, M. Inoki, and K. Naruchi, Macromol. Rapid. Commun., 16, 495 (1995).

22. F. Akutsu, M. Inoki, K. Takahashi, T. Yonemura, Y. Kasashima, and K. Naruchi, Polym. J., 28, 1107 (1996). 